\title{
MODELLING OF THE HUMAN ENAMEL LASER ABLATION PROCESS AT THE MESOSCOPIC SCALE
}

\author{
A. Vila Verde ${ }^{1}$, Marta M. D. Ramos ${ }^{1 *}$, R. Mendes Ribeiro ${ }^{1}$, Marshall Stoneham ${ }^{2}$ \\ ${ }^{1}$ Departamento de Física, Universidade do Minho, Campus de Gualtar, 4710-057 BRAGA, \\ PORTUGAL \\ ${ }^{2}$ Department of Physics and Astronomy, University College London, Gower \\ Street, London WC1E 6BT, United Kingdom
}

\begin{abstract}
A mesoscopic simulation of the process of human enamel laser ablation by Er:YAG and $\mathrm{CO}_{2}$ lasers is being developed using the finite element method, taking into account the complex structure and chemical composition of this material.

A geometric model that allows studying in detail the temperature, stress and displacement distribution within a few enamel rods is presented. The heat generation that takes place inside the enamel at the centre of the laser spot, caused by a non-ablative laser pulse emitted by $\mathrm{CO}_{2}$ and Er:YAG lasers, was simulated. The sensitivity of our model to the estimated material parameters was studied. Temperature, displacement and stress distribution maps obtained for both lasers are presented. These preliminary results suggest that the temperature distribution across the enamel rods is different in the two situations considered; thermally induced stresses in the material are higher in the regions that are richer in hydroxyapatite (HA), and the higher displacements are observed in the regions that are rich in water. The rod tails inside enamel present higher stresses in the direction perpendicular to the surface of enamel than the ones that are created at the surface of our simulated structure. We conclude that the mesostructure plays a crucial role in the accurate modelling of dental laser ablation.
\end{abstract}

Keywords: mesoscopic modelling, laser ablation, human dental enamel, finite element method, $\mathrm{CO}_{2}$ laser, Er:YAG laser

\section{INTRODUCTION}

Conventional dental treatment of cavities removes much more material than that which is diseased, and it is poorly accepted by patients, mainly because it is costly, painful and time-consuming.

A new approach to dental treatment of caries is being developed. This approach, which takes advantage of the laser capability of precise tissue machining, uses lasers to produce narrow tunnels instead of large cavities ${ }^{1}$, has several advantages over the conventional treatment: the amount of sound tissue removed is minimized, which increases the tooth's mechanical resistance; the intensity of vibrations during treatment is greatly diminished, which decreases the need for anaesthetics; in addition, the material that has been treated with the laser is more resistant to acid attack by bacteria.

A great deal of experimental work on enamel laser ablation has been conducted recently using several different lasers, for example, $\mathrm{CO}_{2}$ lasers ${ }^{2}$ operating at $9.3 \mu \mathrm{m}, 9.6 \mu \mathrm{m}, 10.3 \mu \mathrm{m}$ and 10.6 $\mu \mathrm{m}$, Er:YAG, Ho:YAG and Er:YSGG ${ }^{3}$, among others. In general, results show that lasers can indeed remove dental hard tissue in a controlled manner. However, before we are able to take full advantage of this potential use of lasers, there are some problems that must still be solved, for example, the relatively low laser ablation rates and the laser effects such as tooth cracking and its excessive heating, which may result in pulp damage if the pulp temperature rises more than $5^{\circ} \mathrm{C}^{4,5}$.

* marta@ fisica.uminho.pt; phone + 351253604 320; fax + 351253678 981; http://www.gfct.fisica.uminho.pt/ 
In order to solve some of these problems for infra-red lasers, previous workers used the finite element method to simulate the heat distribution and mechanical stress in hard dental tissue during and after laser ablation ${ }^{6,7}$. Others carried out analytical work (a continuum model) on thermo-mechanical laser ablation of dental hard tissues ${ }^{8}$. However, these approaches use average material properties for enamel and take no account of the microstructure and inhomogeneous material distribution, and can therefore be misleading since this mesostructure can greatly influence both the absorption and response of the material to radiation.

Since atomistic modelling focuses on too few atoms and too short time-scales to describe the microstructure of the material or the dynamics of its response to radiation, we believe that an approach through mesoscopic modelling, which allows us to consider aspects of the microstructure of the material as well as the time-dependant behaviour of the ablation process, is appropriate. The advantages of this approach are described elsewhere?

Our ultimate aim is to model the laser ablation process of human dental enamel at $\lambda=10.6 \mu \mathrm{m}$ and $\lambda=2.94 \mu \mathrm{m}$, $\left(\mathrm{CO}_{2}\right.$ and Er:YAG lasers, respectively). Both of them are highly absorbed by human dental enamel and are already being used for some types of dental treatments. Our model will be used to study the influence of the laser parameters, such as fluence, pulse duration, laser pulse spatial and temporal profile, repetition frequency and total number of pulses in the ablation process, and thus provide a guidance capability for the optimisation of this process. This model can be easily modified to study other mid infrared wavelengths, between 3 and $12 \mu \mathrm{m}$.

The goal of the work presented here is to evaluate the sensitivity of our models to variations in the different material and computational parameters that were used, and to predict the differences between the effect of the $\mathrm{CO}_{2}$ and the Er:YAG laser on human dental enamel even under "soft" radiation conditions - we used laser fluences well below the ablation threshold and a very short pulse. The preliminary results presented here correspond to an early stage of our dental laser ablation modelling work. However, they already show an important effect of enamel microstructure on laser radiation induced stress that is not intuitively obvious.

\section{MODEL DESCRIPTION}

We used the finite element software $\operatorname{Algor}^{\mathrm{TM}}$ to create the geometric model of enamel and to obtain the temperature, displacement and stress distribution maps caused by absorption of radiation. We first performed thermal heat transfer analyses, using the parameters that correspond to both lasers. From these we obtained the temperature that each node reaches at every time step. After this we performed linear static stress simulations. Based on the temperature reached by each node at a particular time step, we obtained the stress and displacement (distance between the initial position and the final position of the node) experienced by each node.

From the beginning of our work, we aimed to build a model that includes enamel's microstructure. A detailed description of human enamel can be found in ref. 10. Since rods (prisms) are the building bricks of enamel at the micrometer scale, we began by developing a model of an enamel rod.

The initial rod model that was developed has a square cross-section and a length of $100 \mu \mathrm{m}$. The inner core of the rods has the physical properties of hydroxyapatite (HA) at room temperature and is surrounded by a thin layer, representing the water/organic matrix, to which we attributed the physical properties of water at room temperature (see Table 1). We did not consider absorption of radiation by HA at this stage. We performed several heat transfer analyses using this model in order to investigate the effects of model parameters in the temperature distribution maps, such as the cross-section geometry, the number and dimensions of finite elements, and the number and duration of time steps. Our results suggest that the temperature profiles were strongly influenced by cross-section geometry. Therefore, we built and tested several rod models with different cross-section geometries and finite elements.

Fig. 1.

Our enamel rod model used in this work resembles the shape of enamel rods more closely and can be seen in 


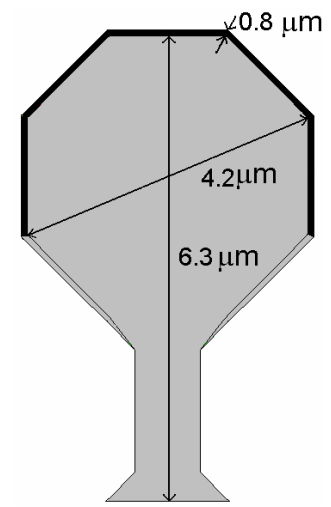

Fig. 1: Cross-sectional view of enamel rod model. The dark area corresponds to the water/organic matrix and the light area to the HA core. The thinner area is termed the tail or waist while the wider area is commonly described as the head of the rod.

This basic three-dimensional structure can be repeated so that we can create models that represent an ensemble of enamel rods (e.g. see Fig. 2). Based on it we developed two models for enamel that, geometrically, differ in length only: one model has the thickness of $35 \mu \mathrm{m}$ and was used to simulate the $\mathrm{CO}_{2}$ laser interaction with enamel; the other model was $25 \mu \mathrm{m}$ thick and was used for the Er:YAG laser. The enamel model for Er:YAG was made shorter than for $\mathrm{CO}_{2}$ because initial simulations indicated that, below a $25 \mu \mathrm{m}$ depth, no appreciable temperature change was observed.

All the nodes were given an initial temperature of $37^{\circ} \mathrm{C}$. The physical properties ${ }^{4,11-15}$, assigned to the rod model materials are given in Table 1 . Based on the geometry on the model and on the mass density of the materials, the percentage of organic material in the model is $4 \%$ by volume, or $1.3 \%$ by weight. As a first approximation, the absorption coefficient of the water/organic at $\lambda=2.94 \mu \mathrm{m}$, the thermal conductivity, the specific heat, the mass density and the thermal expansion coefficient of the water/organic part were considered as those of pure water. The absorption coefficient of HA at $\lambda=2.94 \mu \mathrm{m}$ was not available in the literature, to the best of our knowledge, so it was estimated based on the vol $\%$ of organic material and the absorption coefficient of enamel $\left(800 \mathrm{~cm}^{-1}\right)^{16}$ and water $\left(12250 \mathrm{~cm}^{-1}\right)^{15}$ at this wavelength. The absorption coefficients of HA and water at $\lambda=10.6 \mu \mathrm{m}$ were considered to be equal and were given the value found in ref. $17\left(825 \mathrm{~cm}^{-1}\right)$ for human dental enamel, since the estimated value for HA was similar to the water value $\left(860 \mathrm{~cm}^{-1}\right)^{4}$. The Poisson's ratio and the modulus of elasticity for the water/organic were estimated, since, to the best of our knowledge, there are no available values in the literature. The modulus of elasticity was calculated based on the volume percentage of both materials and the experimental values for enamel (120 GPa $)^{18}$. The Poisson's ratio for the water/organic was considered to be the same as that of HA.

Table 1: Material parameters used in the simulations

\begin{tabular}{|c|c|c|c|c|}
\hline & Water/organic & HA & $\begin{array}{c}\text { Restrain } \\
\text { layer } 1\end{array}$ & $\begin{array}{l}\text { Restrain } \\
\text { layer } 2\end{array}$ \\
\hline $\begin{array}{l}\text { Absorption coefficient at } \\
2.94 \mu \mathrm{m}\left(\mathrm{m}^{-1}\right)\end{array}$ & $1.225 \times 10^{6}$ & $3.0 \times 10^{4}$ & $\begin{array}{c}\text { Not } \\
\text { Applicable }\end{array}$ & NA \\
\hline $\begin{array}{l}\text { Absorption coefficient at } \\
10.6 \mu \mathrm{m}\left(\mathrm{m}^{-1}\right)\end{array}$ & $8.25 \times 10^{4}$ & $8.25 \times 10^{4}$ & NA & NA \\
\hline $\begin{array}{l}\text { Thermal conductivity } \\
\left(\mathrm{J} /\left(\mathrm{s} . \mathrm{m} .{ }^{\circ} \mathrm{C}\right)\right)\end{array}$ & 0.6 & 1.3 & NA & NA \\
\hline $\begin{array}{l}\text { Specific heat } \\
\left(\mathrm{J} /\left(\text { kg. }^{\circ} \mathrm{C}\right)\right)\end{array}$ & $4.2 \times 10^{3}$ & $8.8 \times 10^{2}$ & NA & NA \\
\hline Young's modulus $\left(\mathrm{N} / \mathrm{m}^{2}\right)$ & $1.9 \times 10^{10}$ & $1.1 \times 10^{11}$ & $5.0 \times 10^{7}$ & $6.5 \times 10^{7}$ \\
\hline Poisson's ratio & 0.28 & 0.28 & 0.28 & 0.28 \\
\hline $\begin{array}{l}\text { Thermal expansion } \\
\text { coefficient }\left(\mathrm{K}^{-1}\right)\end{array}$ & $5 \times 10^{-4}$ & $1.6 \times 10^{-5}$ & 0 & 0 \\
\hline $\begin{array}{l}\text { Mass density } \\
\left(\mathrm{kg} / \mathrm{m}^{3}\right)\end{array}$ & $1.0 \times 10^{3}$ & $3.1 \times 10^{3}$ & $3.1 \times 10^{3}$ & $3.1 \times 10^{3}$ \\
\hline
\end{tabular}


We did not consider temperature-dependant material properties. During the thermal analyses the elements at the bottom of both models act as a heat sink: they were given the properties of HA but a mass density of $3.1 \times 10^{6} \mathrm{~kg} / \mathrm{m}^{3}$, instead of the value listed in Table 1 , so that heat transfer to the bulk could be included in the model without increasing both the model's size and the calculation time. In Fig. 2 all the elements which include nodes with coordinate $\mathrm{z}=35 \mu \mathrm{m}$ (the bottom layer of elements) and in Fig. 3 all the elements which include nodes with coordinate $\mathrm{z}=25 \mu \mathrm{m}$ have a mass density of $3.1 \times 10^{6} \mathrm{~kg} / \mathrm{m}^{3}$.

All the external nodes were fixed in the stress analyses, with the exception of the nodes on the top surface $(\mathrm{z}=$ 0 ), which were unconstrained. However, with no other constraints, this could lead to unreliable results, because we are not accounting for the fact that the simulated structure is under the influence of the rest of the material. In order to account for this, we modified our models for the stress analyses. We defined an outer layer of elements (see figure 4) that makes the transition between the fixed nodes and the centre of our model structure. The elements that belong to that layer were given different values for the Young's modulus and Poisson's ratio than the ones used for HA or the organic/water. These values were estimated so that this outer layer, named restrain layer, simulated the constraining effect of the bulk of the material on our structure. We assume that enamel obeys a linear elastic relation between stress and strain until it fractures. The relation can be written as

$$
\sigma=\mathrm{E} . \Delta \ell / \ell
$$

where $\sigma$ is the stress, $\mathrm{E}$ is the Young's modulus of the material, $\Delta \ell$ is the elongation suffered by the material and $\ell$ is the initial length of the bar. Since we want to simulate the effect of the bulk material on our structure, the stress and elongation suffered by any node at the inner part of that layer (for example, node A in figure 4,) should have the same value as if that node were under the influence of the enamel bulk. Therefore

$$
\mathrm{E}_{\text {layer }}=\mathrm{E}_{\text {bulk }} \cdot \ell_{\text {layer }} / \ell_{\text {bulk }} \text {. }
$$

We estimated the Young's modulus values for the outer layers of material assuming that the model structure is surrounded by $5 \mathrm{~mm}$ of enamel, taking the Young's modulus for enamel as $120 \mathrm{GPa}$ and considering that the thickness of the layers is $2.4 \mu \mathrm{m}$ for restrain layer 1 and $3.2 \mu \mathrm{m}$ for restrain layer 2 (see Fig. 4 and Table 1).

The laser parameters used in the simulations are given in Table 2. The values used for the absorbed fluence are significantly inferior to the threshold values for ablation and the duration of the laser pulse does not correspond to a duration available in any commercial laser that we are aware. These values were chosen because our aim was to investigate enamel's response to radiation using fluences below the ablation threshold and determine whether we can predict differences between the $\mathrm{CO}_{2}$ and the Er:YAG in the temperature, stress and displacement maps under those conditions. Using these values, the maximum temperatures reached at the centre of the laser spot are $150-160^{\circ} \mathrm{C}$ so we do not need to consider large material deformation during the laser pulse, since the water pressure build up inside pores will not be enough to create cracking and the material parameters will not vary significantly from their room temperature values.

Scattering in enamel can be neglected at $10.6 \mu \mathrm{m}$; therefore, the energy deposition is determined by this tissue's absorption coefficient and reflectance. The reflectance has a value of $13 \%$ at $\lambda=10.6 \mu \mathrm{m}^{19}$. Thus, we can consider in first approximation that all the incident radiation is absorbed and transformed into internal kinetic energy of the material. The scattering of enamel at $2.94 \mu \mathrm{m}$ cannot be found in literature, to the best of our knowledge. It is estimated that it is negligible, because the absorption coefficient of enamel at this wavelength is high $\left(800 \mathrm{~cm}^{-1}\right)^{16}$ and, therefore, all the radiation is absorbed within the first micrometers of tissue ${ }^{20}$. The main effect of scattering would be to alter the lateral distribution of the energy absorption. However, at this point we cannot confidently relate the absorbed and incident fluence in enamel at this wavelength. We considered that the laser beam is perpendicular to the surface of the model, that is, the optical axis of the laser beam is parallel to the longitudinal axis of the enamel rods. The intensity of the laser beam inside the tissue at every instant is given by:

$$
\mathrm{I}(\mathrm{r}, \mathrm{z})=\mathrm{I}_{0} \cdot \exp (-\alpha \cdot \mathrm{z}) \cdot \exp \left(-2 \mathrm{r}^{2} / w^{2}\right)
$$

where $\underline{\mathrm{z}}$ is the depth inside the tissue, $\underline{\mathrm{I}}_{0}$ is the intensity of radiation at the surface of the target, $\underline{\alpha}$ is the absorption coefficient of the tissue, $\underline{w}$ is the beam waist and $\underline{r}$ is the radial distance from the centre of the laser spot ${ }^{4}$. It should be noted that the intensity of the laser beam is constant over time. The local heat deposition, S, per unit area and time over a slice of material with thickness $\Delta \mathrm{z}$ is given by 


$$
S(r, z)=-\frac{\partial I(r, z)}{\partial z}=\alpha . I(r, z)
$$

The absorption of radiation by the tissue was simulated by generating heat in certain elements. The heat generating value was considered constant over each element and calculated according to eqn. (4) by taking the coordinates of one of the element's nodes.

Table 2: Laser parameters

\begin{tabular}{|l|c|c|}
\hline Type of laser & $\mathrm{CO}_{2}(10.6 \mu \mathrm{m})$ & Er:YAG $(2.94 \mu \mathrm{m})$ \\
\hline Pulse duration $(\mu \mathrm{s})$ & 0.35 & 0.35 \\
\hline $\begin{array}{l}\text { Maximum absorbed intensity, } \\
\mathrm{I}_{0}\left({\mathrm{~J} . \mathrm{m}^{-2}}^{-1} \mathrm{~s}^{-1}\right)\end{array}$ & $1.2 \times 10^{10}$ & $6.2 \times 10^{9}$ \\
\hline Number of pulses & 1 & 1 \\
\hline Beam waist $(\mathrm{mm})$ & 0.2 & 0.2 \\
\hline
\end{tabular}

\section{RESULTS AND DISCUSSION}

\subsection{Influence of material parameters on the results}

We tested the sensitivity of our models to changes in the following parameters: duration and number of time steps, dimensions and number of finite elements, mass density, thermal conductivity, specific heat, Young's modulus, shear modulus and thermal expansion coefficient of the organic/water and the HA. The reference values and maps correspond to simulations that used the parameters shown on tables 1 and 2.

We performed thermal simulations using 40 and 100 time steps; the temperature maps obtained are qualitatively and quantitatively identical. Therefore, apart from the initial simulation, all the thermal simulations used 40 time steps. The total time simulated was not exactly the same in all the thermal simulations performed, so the duration of the time steps varied between $0.01 \mu \mathrm{s}$ and $0.0125 \mu \mathrm{s}$.

We also performed thermal simulations with meshes that were significantly coarser and finer than the one we used to obtain all the results that are presented in this work, so that we could be certain of the adequacy of the mesh we used.

We varied the value of the mass density of HA between $2900 \mathrm{~kg} \cdot \mathrm{m}^{-3}$ and $3150 \mathrm{~kg} \cdot \mathrm{m}^{-3}$. The temperature distribution maps obtained using these values remained qualitatively identical, and the maximum temperatures reached varied by $3 \%$ compared to the reference values. The mass density of the organic/water part was varied between $995 \mathrm{~kg} \cdot \mathrm{m}^{-3}$ and $1005 \mathrm{~kg} \cdot \mathrm{m}^{-3}$. No differences were observed on the temperature maps.

Varying the values of the thermal conductivity of water/organic and HA and the specific heat of water by \pm $15 \%$ did not induce any changes on the temperature maps, which indicates that the model is not sensitive to these parameters. Varying the specific heat of HA by $\pm 15 \%$, however, led to some changes on the temperature maps; for example, the maximum temperature reached varied by $\pm 10 \%$. Qualitatively, however, the temperature maps remained unchanged.

The values of the modulus of elasticity of the restrain layers used in the stress analysis were varied by plus or minus one order of magnitude in relation to the values displayed on Table 2, and the displacement maps obtained were qualitatively and quantitatively identical. The results reported so far indicate that our model is not highly sensitive to the values estimated for the mass density, thermal conductivity and specific heat of water/organic and HA, as well as the Young's modulus for the restrain layers.

The value of the modulus of elasticity of water/organic was varied between 17 and $19 \mathrm{GPa}$ while the shear modulus was varied between $7 \mathrm{GPa}$ and $9 \mathrm{GPa}$, so that Poisson's ratio remained constant. The value of the same 
parameters for HA was varied between $95 \mathrm{GPa}$ and $130 \mathrm{GPa}$ (Young's modulus) and $37 \mathrm{GPa}$ and $51 \mathrm{GPa}$ (shear modulus). The displacement maps were not modified by the use of these values, but the stress maps over the $\mathrm{Z}$ direction did show a quantitative modification: the maximum stress observed was, in the worst case, $16 \%$ higher than the reference value. This indicates that our results are sensitive to the values used for Young's modulus and shear modulus, so in the future good estimates of these values will be necessary in order to have reliable quantitative predictions for cracking and ablation.

The thermal expansion coefficients, $\alpha$, of water and HA were separately varied by plus or minus one order of magnitude in relation to the values in Table 1 . Making $\alpha_{\text {water/organic }}$ one order of magnitude larger than the reference caused the values of stress in the $\mathrm{Z}$ direction and displacement, at the centre of the laser spot, to increase by one order of magnitude. An $\alpha_{\text {water/organic }}$ value one order of magnitude lower than the reference led the values of stress over $Z$ to decrease by one order of magnitude, even though the maximum displacement values at the centre of the structure only decreased by $40 \%$. Using a $\alpha_{\mathrm{HA}}$ one order of magnitude larger than the reference caused the displacement values at the centre of the structure to be one order of magnitude larger, even though the maximum values of the stress in the $Z$ direction actually decrease by $15 \%$. Using a $\alpha_{\mathrm{HA}}$ value one order of magnitude lower caused the maximum displacements to decrease by $60 \%$, even though the maximum stress over the $\mathrm{Z}$ direction only varied by $6 \%$. Despite the fact that no significant qualitative changes were found in both stress and displacement maps, these results indicate that the model is highly sensitive to the thermal expansion coefficient from a quantitative point of view, a fact for which any future work will have to account.

Our results indicate that our model is not highly sensitive, from a qualitative point of view, to the value of any of the material parameters that we tested. However, from a quantitative point of view, our results show that our model is highly sensitive to the value of the thermal expansion coefficient used for water/organic and for HA and moderately sensitive to the values of the modulus of elasticity and Poisson's ratio. Good estimates of these values will be necessary to have reliable quantitative predictions. Accurate experimental data would be welcome.

\subsection{Comparison of Er:YAG versus $\mathrm{CO}_{2}$}

The temperature maps obtained for the $\mathrm{CO}_{2}$ and the Er:YAG can be seen in figures 2 and 3 .

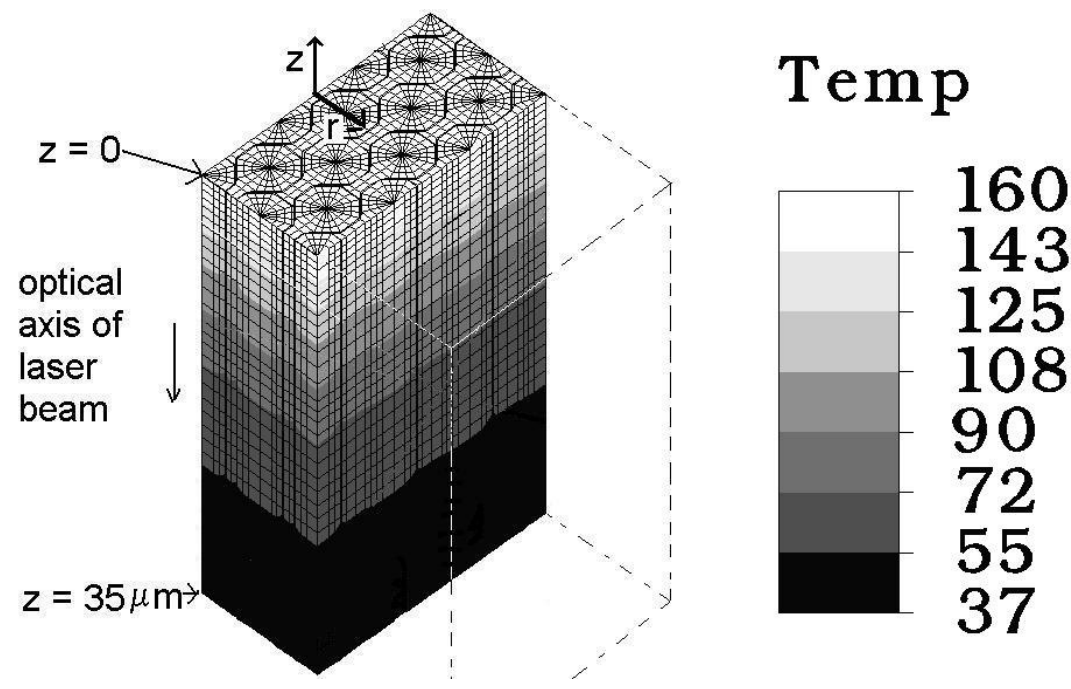

Fig. 2: Temperature $\left({ }^{\circ} \mathrm{C}\right)$ map of enamel irradiated by the $\mathrm{CO}_{2}$ laser at the end of a $0.35 \mu$ s laser pulse. The model was sectioned in half so that we could observe the temperature distribution inside the model structure. 


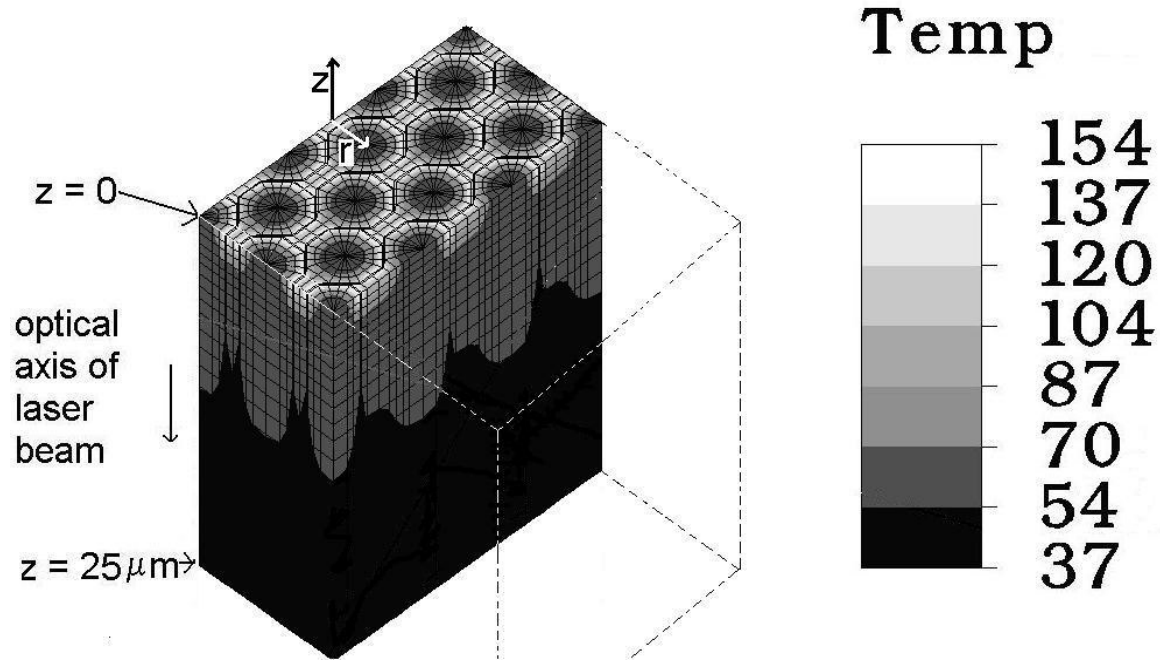

Fig. 3: Temperature $\left({ }^{\circ} \mathrm{C}\right)$ map of enamel irradiated by the Er:YAG laser at the end of a $0.35 \mu$ s laser pulse. The model was sectioned in half so that we could observe the temperature distribution inside the model structure.

Even though the maximum temperature reached is the same, the temperature maps are qualitatively different. Using a $\mathrm{CO}_{2}$ laser, the water and the enamel parts attain similar temperatures, so the temperature distribution appears to be uniform across the $\mathrm{XY}$ planes. The most significant temperature gradients appear on the $\mathrm{Z}$ direction. Using an Er:YAG laser, it can be seen that the water reaches a much higher temperature than HA. The temperature distribution obtained is highly inhomogeneous across the XY planes. The minimum temperature difference between the centre of the enamel rods and the water/organic sheath is $70^{\circ} \mathrm{C}$, which creates a minimum temperature gradient in the $\mathrm{XY}$ plane of $35^{\circ} \mathrm{C} / \mu \mathrm{m}$.

The displacement maps obtained for the $\mathrm{CO}_{2}$ and the Er:YAG can be seen on figures 4 and 5 .

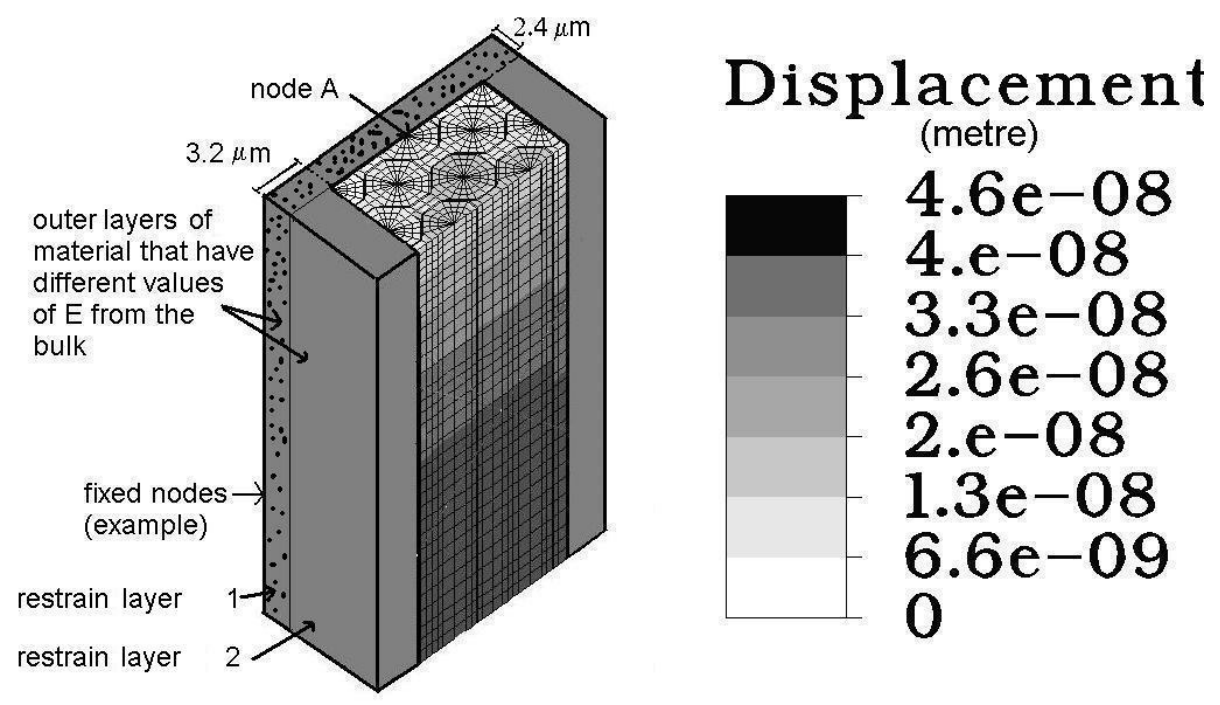

Fig. 4: Displacement map obtained from the temperature values on Fig. $2\left(\mathrm{CO}_{2}\right.$ laser $)$. 

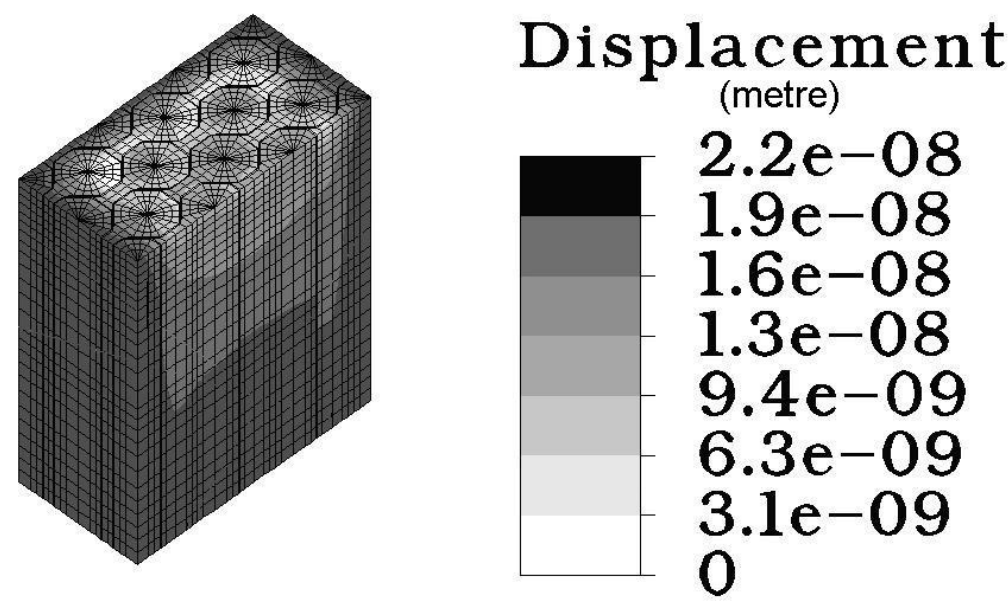

Fig. 5: Displacement map obtained from the temperature values on Fig. 2 (Er:YAG laser).

They are qualitatively identical. At the centre of the model structure larger displacements are obtained using a $\mathrm{CO}_{2}$ laser than using the Er:YAG. This is not surprising, even though the maximum temperatures reached are the same, because the temperature rise suffered by $\mathrm{HA}$ is much higher when using a $\mathrm{CO}_{2}$ laser than when using a Er:YAG. This causes the HA to dilate more in the $\mathrm{CO}_{2}$ case than in the Er:YAG case.

The maps of stress over the $\mathrm{Z}$ direction can be seen on fig. 6 and 7 and are qualitatively identical.

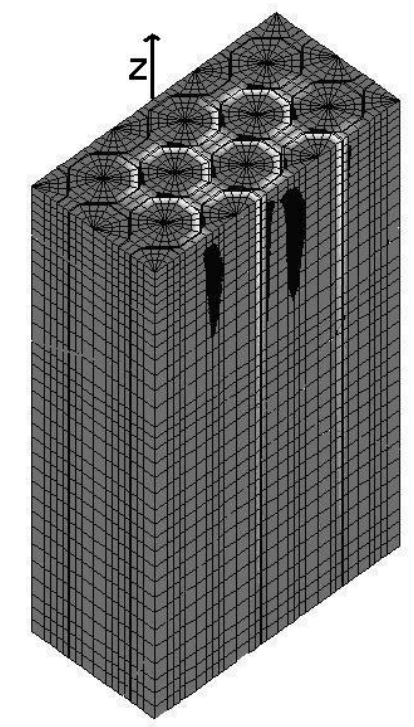

\section{Tensor}

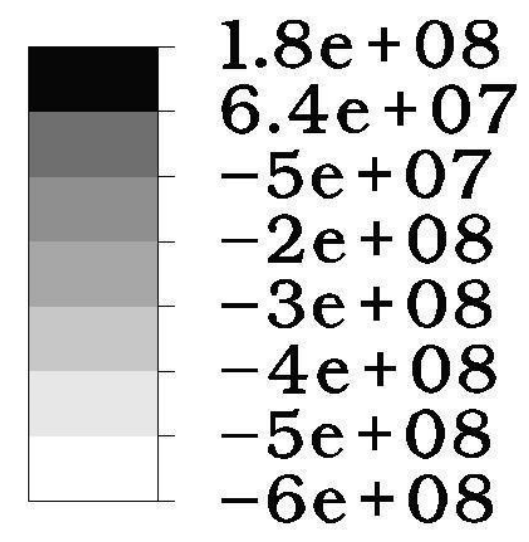

Fig. 6: Component of stress $\left(\mathrm{N} / \mathrm{m}^{2}\right)$ parallel to $\mathrm{OZ}$, obtained from the temperature values in Fig. $2\left(\mathrm{CO}_{2}\right)$. In each finite element, a positive value of stress indicates that it is under tension over the $\mathrm{Z}$ direction; a negative value indicates that that element is being compressed over the $\mathrm{Z}$ direction. 


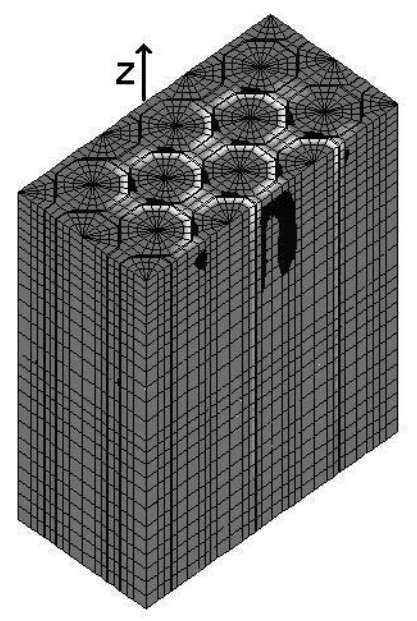

\section{Tensor}

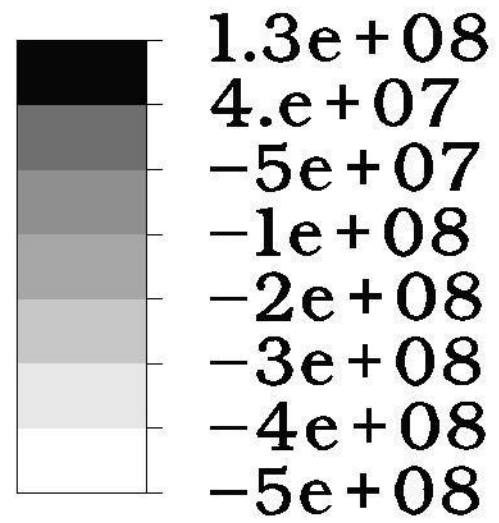

Fig. 7: Component of stress $\left(\mathrm{N} / \mathrm{m}^{2}\right)$ parallel to OZ, obtained from the temperature values in Fig. 2 (Er:YAG). In each finite element, a positive value of stress indicates that it is under tension over the $\mathrm{Z}$ direction; a negative value indicates that that element is being compressed over the $\mathrm{Z}$ direction.

It can be seen in both figures that some inner zones of enamel (close to the surface), located at the tail of the enamel rods, have higher stress values in the $\mathrm{Z}$ direction than the finite elements above them. These preliminary results suggest that the tail of the enamel rods is mechanically weaker than the head, and also that during the ablation process some internal stress generation may take place that can be responsible for the desired removal of material and unwanted tooth cracking.

These preliminary results suggest that, even under soft radiation conditions, the Er:YAG and the $\mathrm{CO}_{2}$ lasers lead to qualitatively different temperature distributions within enamel and that the enamel microstructure has an important effect on the thermally induced stresses.

\section{CONCLUSIONS}

Our results indicate that our model is not highly sensitive, from a qualitative point of view, to the value of any of the material parameters. They also indicate that (within the range of values that we tested) our model is highly sensitive, from a quantitative point of view, to the value of the thermal expansion coefficient used for water/organic and for HA and moderately sensitive to the values of the modulus of elasticity and Poisson's ratio. Good experimental estimates of these values will be necessary in order to obtain reliable quantitative predictions.

Results also suggest that the tail of the enamel rods is mechanically weaker than the head, and that higher stresses over the $\mathrm{Z}$ direction are generated inside the enamel, at the tail of the enamel rods, than on the surface directly above that area. This may have direct implications on the laser ablation and pre-cracking mechanisms. The enamel microstructure also seems to influence greatly the temperature distribution caused by the Er:YAG and $\mathrm{CO}_{2}$ lasers.

Future work will also include further validation of our models, development of models that allow us to study the effect of the spatial profile of the laser beam simulation on the temperature, stress and displacement distribution 
over the material and inclusion of material removal using a more refined finite element model, with temperature dependent material properties.

\section{ACKNOWLEDGEMENTS}

This work was approved by the Portuguese Foundation for Science and Technology, FCT, and POCTI, and supported by the European Community Fund FEDER under project no. POCTI/ESP/37944/2001. One of us (A.V.V.) is also indebted to FCT for financial support under PhD grant no. SFRH/BD/4725/2001. The authors wish to thank Drs. G. Dias and J. Carneiro from University of Minho and Professors G. Pearson and Jim Elliot from Queen Mary Westfield College, London, for helpful discussions in the course of this work.

\section{REFERENCES}

1. G. J. Pearson, "The application of excimer laser radiation to dental hard tissue", Nanobiology, Vol. 3, pp. 223-232, 1994.

2. D. Fried, J. Ragadio, M. Akrivou, J. Featherstone, M. W. Murray and K. M. Dickenson, "Dental hard tissue modification and removal using sealed transverse excited atmospheric-pressure lasers operating at 9.6 and 10.6 micrometers", Journal of Biomedical Optics, Vol. 6, 2, pp. 23 -238, 2001.

3. D. Fried, "IR laser ablation of dental enamel", Lasers in Dentistry VI, Ed. J. Featherstone, P. Rechmann and D. Fried, Vol. 3910, pp. 136-148, SPIE, San Jose, California, USA, 2000.

4. M. Niemz, Laser-Tissue Interactions - Fundamentals and applications, Springer-Verlag, Berlin, 1996.

5. L. Zach and G. Cohen, "Pulp response to externally applied heat", Oral Surgery Oral Medicine Oral Pathology Oral Radiology and Endodontics, Vol. 19, 4, pp. 515-530, 1965.

6. G. Uhrig, D. Meyer and H.-J. Foth, "Transient FEM calculation of the spatial heat distribution in hard dental tissue during and after IR laser ablation", Lasers in dentistry VII, Ed. P. Rechmann, D. Fried and T. Hennig, Vol. 4249, pp. 61-71, San Jose, California, USA, 2001.

7. G. Uhrig and H.-J. Foth, "Thermal and mechanical stress in hard dental tissue under IR laser ablation", Lasers in Dentistry VI, Ed. J. Featherstone, P. Rechmann and D. Fried, Vol. 3910, pp. 149-157, San Jose, California, USA, 2000 .

8. B. Majaron and M. Lukac, "Thermo-mechanical laser ablation of hard dental tissues: an overview of effects, regimes, and models", Lasers in dentistry V, Ed. SPIE, Vol. 3593, pp. 184-195, San Jose, California, USA, 1999.

9. M. Stoneham, M. M. D. Ramos and R. M. Ribeiro, "The mesoscopic modelling of laser ablation", Applied Physics A, Vol. 69, supplement, pp. s81-s86, 1999.

10. M. E. G. Ferraris and A. Campos Muñoz, Histología y Embriología bucodental, pp. 128-266, Editorial medica panamericana, Madrid, 1999.

11. G.V. Samsonov (Ed), The oxide handbook, 2IFI/PLENUM, New York, USA, 1982.

12. H. H. Moroi, K. Okimoto, R. Moroi and Y. Terada, " Numeric approach to the biomechanical analysis of thermal effects in coated implants", Int.J.Prosthodont, Vol. 6, pp. 564-572, 1993.

13. American Mineralogist, vol. 074, 1989, pp. 870.

14. E. Grenoble, Katz J L, K. L. Dunn, R. S. Gilmore and K. L. Murty, "The elastic properties of hard tissues and apatites", J biomed mater res, Vol. 6, 3, pp. 221-223, 1972. 
15. G. M. Hale and M. R. Querry, "Optical constants of water in the $200 \mathrm{~nm}$ to 200 micrometer wavelength region", Appl.Opt., 12, pp. 555-563, 1973.

16. D. Fried, M. J. Zuerlein, J. Featherstone, W. Seka, C. Duhn and S. M. McCormack, "IR laser ablation of dental enamel: mechanistic dependance on the primary absorber", Applied Surface Science, Vol. 127-129, pp. 852-856, 1998.

17. M. J. Zuerlein, D. Fried, J. D. B. Featherstone and W. Seka, "Optical properties of dental enamel in the mid-IR determined by pulsed photothermal radiometry", Ieee Journal of Selected Topics in Quantum Electronics, Vol. 5, 4, pp. 1083-1089, 1999.

18. J. L. Cuy, A. B. Mann, K. J. Livi, M. F. Teaford and T. P. Weihs, "Nanoindentation mapping of the mechanical properties of human molar tooth enamel ", Arch.Oral.Biol., Vol. 47, pp. 281-291, 2002.

19. D. Fried, R. E. Glena, J. D. B. Featherstone and W. Seka, "Permanent and transient changes in the reflectance of $\mathrm{CO}_{2}$ laser-irradiated dental hard tissues at $\mathrm{l}=9.3,9.6,10.3$, and $10.6 \mathrm{~mm}$ and at fluences of $1-20 \mathrm{~J} / \mathrm{cm}^{2}$ ", Lasers in Surgery and Medicine, Vol. 20, 1, pp. 22-31, 1997.

20. D. Fried, W. Seka, J. D. B. Featherstone and R. E. Glena, "Nature of light-scattering in dental enamel and dentin at visible and near-infrared wavelengths ", APPLIED OPTICS, Vol. 34, 7, pp. 1278-1285, 1995. 